\title{
Learning Theory, Lecture, and Programmed Instruction Text: An Experiment in Bibliographic Instruction
}

\begin{abstract}
Freshmen at two midwestern institutions of higher education participated in a bibliographic instruction experiment. A three-element model was used that considered the interaction of library tools, styles or modes of instruction, and a theory of learning. Comparisons were made between lecture and programmed instruction text in the teaching of bibliographic indexes and basic catalog card information. The learning hierarchy of Robert M. Gagné was used for three levels of learning: factual, conceptual, and application or problem solving. Results indicate a superiority of programmed instruction at the factual and problem-solving levels and the necessity for further experimentation.
\end{abstract}

$\mathrm{S}$ concern, debates about bibliographic instruction have moved from considerations of simple implementation techniques and problems to a recognition that it is a complex process which requires a wide range of approaches. ${ }^{1}$ In this transition, academic librarians have discovered the work on learning theory and have begun to apply it to library instruction. ${ }^{2}$ Attention is also being devoted to the processes by which students can be taught, from the traditional lecture method to technologically sophisticated instruction. Many librarians have concluded that a combination of teaching tools and techniques is desirable in order to meet all educational goals. ${ }^{3}$

It has become apparent in the last few years that the bibliographic instruction process requires a combination of three elements: (1) selection of specific tools for instruction, (2) identification of the style or mode of learning intended, and (3) selection of the proper type of instruction.

Thomas T. Surprenant is assistant professor, Graduate Library School, University of Rhode Island, Kingston.
Figure 1 represents a model of these elements. A selection of library tools, types of instruction, and types of learning is made that results in the convergence (darkened area) necessary for learning to take place.

The intent of the experiment described in this paper was to study the effects of the convergence, or intersection, of the three circles (figure 1) on the bibliographic instruction process.

\section{PlanNing for Instruction}

The most elementary bibliographic tools to instruct freshmen were selected in order to eliminate any difficulty that might result from the use of more complicated tools. Those selected were the Readers' Guide to Periodical Literature, Applied Science and Technology Index, the Social Sciences and Humanities indexes, and catalog card information. The learning hierarchy proposed by Robert M. Gagné was used to determine the three types of learning necessary for the use of the bibliographic tools, i.e., factual, conceptual, and application or problem solving. ${ }^{4}$ Table 1 shows examples of how these tools utilize the Gagné hierarchy.

Consideration of the results of the research 


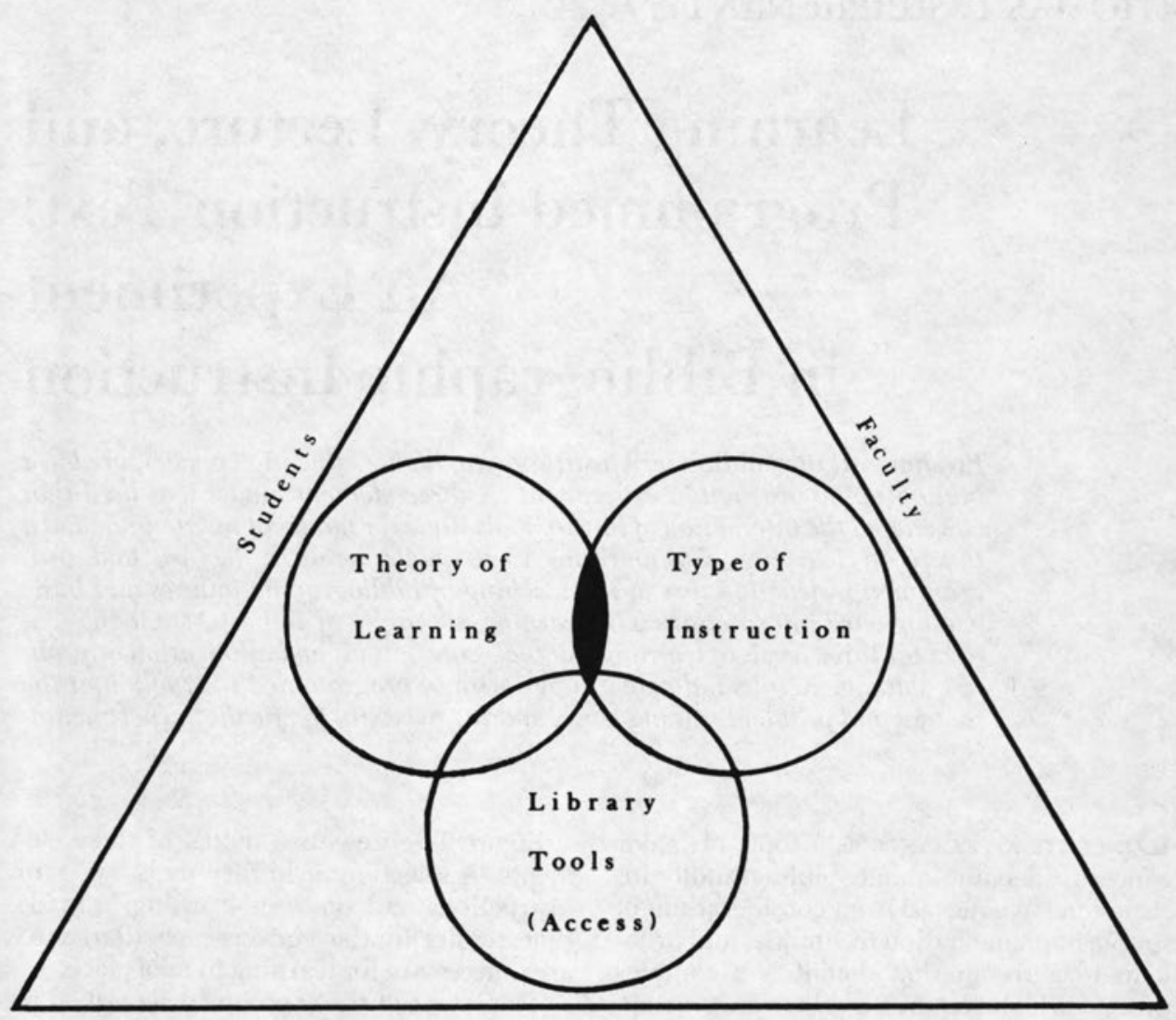

Librarians

Fig. 1

Bibliographic Instruction Model

by Allen, which compared the types of media to particular types of learning, pointed to the use of the traditional lecture method in a comparison with a programmed instruction text. ${ }^{5}$ When all three elements, consisting of library tools, a theory of learning, and types of instruction, were considered, the specific model shown in figure 2 was the result.

In order to perform the experiment, a number of questions were formulated.

1. Would the overall test scores of those who were instructed by lecture and programmed instruction text differ significantly from the scores of those who received no instruction?

2. Would the overall test scores of those who were instructed by lecture differ from the scores of those who had received the pro- grammed text instruction?

3. Would there be a significant difference between those who received the lecture and those who received the programmed instruction text at the factual, conceptual, and application levels of learning?

\section{THE EXPERIMENT}

The experiment utilized a research design that consisted of four groups, two instructional (or experimental) and two that received no instruction (or control). ${ }^{6}$ Table 2 represents the experimental design.

The principles of instructional design, standard research practices, and the developmental model presented by Pipe were used in the design and validation of the lecture and programmed instruction text. ${ }^{7}$ Behavioral 
TABLL 1

EXAMPLeS of Matchup BIBLIOGRAPHIC ToOLS AND LEVELS OF LEARNING

\begin{tabular}{ll}
\hline Level & \multicolumn{1}{c}{ Example } \\
\hline Factual & $\begin{array}{l}\text { There are three types of catalog } \\
\text { cards: author, title, subject. Periodi- } \\
\text { cal indexes are arranged primarily } \\
\text { by subject. } \\
\text { Both periodical indexes and catalog } \\
\text { cards are analogs of the collections, } \\
\text { i.e., they represent ways of provid- } \\
\text { ing access to the collection. }\end{array}$ \\
Application & $\begin{array}{l}\text { Demonstrated ability to locate and } \\
\text { identify component parts of a biblio- } \\
\text { graphic citation. }\end{array}$
\end{tabular}

objectives for the students who would be learning how to use the bibliographic indexes and basic catalog card information were formulated, and a text that would measure knowledge before instruction and at the completion of instruction was prepared.

The writing of the programmed instruction text was accomplished in three stages. First, portions of the text were written, and a group of six freshmen commented in both written and oral forms on each section. From
TABLE 2

Experimental Design SOLOMON Four

\begin{tabular}{lccc}
\hline & Pretest & Instruction & Posttest \\
\hline I $(R)$ & $0_{1}$ & $x$ & $0_{2}$ \\
II $(R)$ & $0_{3}$ & & $0_{4}$ \\
III $(R)$ & & $x$ & $0_{5}$ \\
IV $(R)$ & & & $0_{6}$ \\
\hline
\end{tabular}

$(R)=$ random assignment

$0_{1}-0_{e}=$ test or measurement

$x=$ instruction

Groups I and III are instructional groups and groups II and IV receive no instruction.

their comments, revisions were made and a rough draft of the entire text was completed. The rough draft was circulated to ten academic librarians and the six students for comments and criticism. A further revision was made and the text was circulated a final time.

The lecture was drawn from the programmed instruction text and included a set of fourteen transparencies to provide the same examples as those given in the text. The lecture was designed to be a duplicate of the text without the practice questions.

A pretest of all of the materials was run at

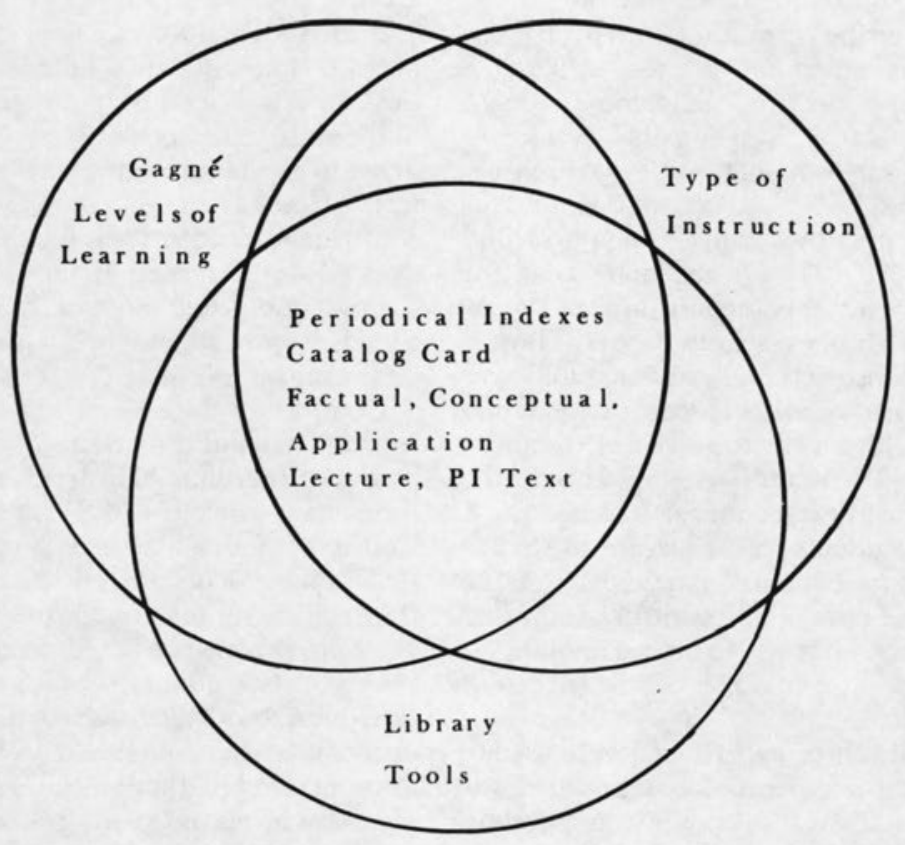

Fig. 2

A Specific Bibliographic Instruction Model 
the College of St. Scholastica, Duluth, Minnesota, in early December of 1977. A total of eighty-five students participated in the validation test, with seventy-nine usable responses. On average, the test took twentyfive minutes. An evaluation of the procedures used determined that they were adequate for the study. Test scores were checked for internal consistency using KR20, a statistical test measuring consistency for two alternative test items. The KR20 statistic was .92 for the tests, indicating a high degree of internal consistency. Given the high reliability, no further revisions were made.

Freshmen from Michigan Technological University (MTU) and the University of Minnesota, Duluth (UMD), participated in the experiment. MTU had forty-six sections of freshmen English courses with a limit of twenty-eight students per section. UMD had twenty-nine sections with a limit of twenty students per section. Thus, the total possible number of students participating in the experiment was 1,868 . Since the students were already registered for the second-quarter classes, randomization was achieved on the basis of sections instead of individual students. An outside consultant employed standard mathematical procedures, utilizing a programmable electronic calculator random number generator to assign the sections to one of the four elements in the research design (see table 2).

The experiment was run during the second quarter of the 1977-78 academic year. At both institutions, it came just prior to the assignment of library research papers. Thus, it fit into the instructional sequence and was directly related to what students were doing at the time. From the total, 1,234 responses were useful. The unusable responses were the result of missing tests and/or instruction. A total of 629 students ( 327 in lecture and 302 in programmed instruction) participated in the instructional phase. The control group had 605 students who received no instruction.

\section{Results AND Discussion}

The results of the experiment were used to test the questions formulated prior to the study. For statistical purposes, the questions were phrased as hypotheses as follows:

$H_{1}$ : Experimental group posttest scores will be greater than control group scores.
$H_{2}$ : Posttest scores of lecture and programmed instruction will be equal.

$\mathrm{H}_{3}$ : Factual posttest scores will be higher in programmed instruction than in lecture.

$H_{4}$ : Application posttest scores for lecture and programmed instruction will be equal.

$H_{5}$ : Conceptual posttest scores will be higher in lecture than in programmed instruction.

Standard checks confirmed the validity (internal and external) of the experiment. ${ }^{8} \mathrm{~A}$ factor analysis of the test scores resulted in dropping $H_{5}$, the conceptual level, from consideration. The factor analysis identified only one question in the pre- and posttest as conceptual. Thus, the reliability of a single test item could not be demonstrated by this hypothesis, and any conclusions were likely to be tenuous.

Prior to data analysis it was decided that any result with probability equal to or less than $\alpha=.05$ would be considered significant. The results of the data collected are summarized in tables 3 and 4 . Table 1 shows the pretest and posttest means and variances for each instructional method and for the control group.

From the results presented in table 3 , it can be seen that students who received instruction, in either lecture or programmed text, did significantly better $(\alpha<.01)$ than students in the control group who received no instruction. Thus, the first hypothesis was confirmed. Students in the control group showed almost no gain in the period between the two tests while those in the experimental groups improved by at least thirteen points on average.

Comparing the lecture and programmed instruction conditions (table 3 ), students who used the programmed instruction text did significantly better $(\alpha<.001)$ than those in the lecture. On the average, programmed instruction students scored six points higher than lecture students on the posttest. Hypothesis two, which predicted no difference between the two groups, was not confirmed.

Table 4 shows the results of the comparison of mean posttest scores for lecture and programmed instruction on the factual and application levels of learning. From table 4, it can be seen that when the two modes of instruction are compared, programmed instruction is significantly better than lecture 
TABLE 3

Pretest and Posttest Scores for Experimental and Control Groups

\begin{tabular}{|c|c|c|c|c|}
\hline $\begin{array}{l}\text { Modes of } \\
\text { Instruction }\end{array}$ & Pretest & Posttest & Differences & $\mathrm{n}$ \\
\hline Lecture & $\begin{array}{l}19.175^{*} \\
(54.989) \dagger\end{array}$ & $\begin{array}{c}30.056 \\
(79.265)\end{array}$ & 10.9 & 327 \\
\hline Programmed instruction & $\begin{array}{l}20.585 \\
(48.552)\end{array}$ & $\begin{array}{c}36.759 \\
(93.289)\end{array}$ & 16 & 302 \\
\hline Combined lecture and PI & $\begin{array}{l}19.88 \\
(51.77)\end{array}$ & $\begin{array}{l}33.408 \\
(86.277)\end{array}$ & 13.5 & (609) \\
\hline $\begin{array}{l}\text { No instruction (control group) } \\
\text { Total }\end{array}$ & 19.343 & 21.084 & $1.7^{* *}$ & $\begin{array}{c}605 \\
1234\end{array}$ \\
\hline
\end{tabular}

-mean score

tvariance

- "non-significant

TABLE 4

Means and Variances: Factual and Application SCORES OF LeCtURE AND Programmed InStruCtion

\begin{tabular}{|c|c|c|c|}
\hline & Lecture & $\begin{array}{l}\text { Mode of Instruct } \\
\text { Programmed } \\
\text { Instruction }\end{array}$ & Total \\
\hline Factual & $\begin{array}{c}7.997^{*} \\
(7.187)^{\dagger}\end{array}$ & $\begin{array}{c}9.977 \\
(8.986)\end{array}$ & $\begin{array}{c}8.948 \\
(9.018)\end{array}$ \\
\hline Application & $\begin{array}{l}20.09 \\
(38.59)\end{array}$ & $\begin{array}{c}23.99 \\
(38.36)\end{array}$ & $\begin{array}{c}21.96 \\
(42.22)\end{array}$ \\
\hline
\end{tabular}

'mean score

†variance

for both factual $(\alpha<.01)$ and application $(\alpha<.001)$ levels of learning. On the factual level, programmed instruction scores are almost two points (1.98) higher than lecture. This difference confirmed the third hypothesis, which identified programmed instruction as superior. The application level shows a difference of almost four points (3.9) in favor of programmed instruction between the two modes of instruction. The fourth hypothesis predicted no significant difference at the application level of learning. This hypothesis was not confirmed.

The control group acted as a check on the validity of the entire process. Checks on the test scores, both before and after the experimental groups received instruction, provided evidence that neither the test itself nor any outside influences could account for the differences in scores.

The second hypothesis predicted that, overall, lecture and programmed instruction would be the same in the posttest scores. However, programmed instruction did significantly better than lecture. It must be pointed out that the lecture benefited from the development of the programmed text for this experiment. Thus, it could not be called a "typical" library lecture.
It should also be pointed out that the same librarian did not give the lecture in all cases: four different librarians participated. Thus, there was not full control because of the differences inherent in each personality and style of presentation. Partial control resulted from the structure of the materials and the time allotted to present them. With a programmed text the lack of uniformity inherent in the lecture was eliminated. Programmed instruction is consistent over time while it is almost impossible for lectures to be consistent, especially when librarians are frequently asked to give the same lecture three or more times in one day.

It is interesting to note, too, that programmed instruction has been considered particularly strong in the presentation of factual information. The results for the third hypothesis reaffirmed that programmed instruction did significantly better than lecture for this type of learning. Programmed instruction is uniquely suited for learning facts. It uses a question-answer format that is more germane to learning factual information than to any other type of learning. On the other hand, a lecture that is a mere recitation of facts is usually considered boring. The good lecturer knows this and tries to enliven the presentation. Thus, extraneous information is often introduced in an attempt to make the lecture more palatable. This can, and often does, disguise the factual information and complicates the entire learning process. Finally, with programmed instruction the answer to what has been presented is elicited almost immediately, while with lecture no answer is required at the time of instruction and the student must wait (often more than half a semester) for a test before there is any feedback. 
The last hypothesis stated that there was no significant difference between lecture and programmed instruction at the application level of learning. The analysis determined that programmed instruction did significantly better than lecture. There is little doubt that programmed instruction provides practice in problem solving as part of its structure. Unless carefully planned, lectures frequently ignore practice for students. Those students who have the programmed text have ample opportunity to review and practice through the question-answer format. Application, or problem solving, is best taught with problem situations in which the learner is required to use what was previously learned in order to work out the correct answer. With more practice, the chances of success are greater. In this experiment, the programmed text exposed the student to practice situations while the lecture did not.

Finally, the author would like to point out, and in some cases emphasize, the advantages that programmed instruction texts have to offer in the bibliographic instruction process. (1) Time is saved once the text is developed and tested. (2) Information is presented in an orderly, uniform way, is consistent over time, and is designed to be self-pacing so that students can learn at their own speed. (3) Flexibility is present in that successful pretesting of what is being learned allows the student to skip through known material to unfamiliar material. Practice is provided that is important in both the learning and retention of basic library skills. (4) The absence of extraneous information that frequently creeps into other forms of instruction makes it easier for students to identify what is important, although not necessarily as exciting, to learn. (5) The form of this mode of instruction makes it easy to assign, either during class time or as an out-of-class assignment. Thus, programmed instruction texts can be more acceptable to faculty - and less threatening. (6) It represents an alternative to the labor-intensive instruction currently offered.

\section{Conclusions}

In this study the programmed instruction text was shown to be a superior mode of instruction to lecture under the conditions stated. Librarians should seriously consider the merits of the programmed instruction text for any instruction that has a large factual component. The success of the programmed instruction text in the area of application or problem solving should encourage further experimentation in this area. Certainly more research is needed in order to strengthen the argument that a programmed instruction text can be used for instruction in problem solving. At least, the results in this area should remind librarians that sufficient practice should be built in, no matter what the mode of instruction. Without practice it is not likely that skill levels can be maintained.

The experiment also pointed to the use of statistical methods to check the validity of the entire instructional sequence. Without the benefit of a check, the conceptual level of learning would have been assumed to be valid. Its elimination after a routine validity check points to the importance of such procedures. It also illustrates human fallibility when identifying levels of learning and attempting to organize instruction utilizing them.

A great deal more experimental research is necessary to examine various ways of teaching students how to use particular library tools. Emphasis should be placed on the types of learning in relation to the modes of instruction. For large groups, lecture may not be as viable as alternative methods. What works at small colleges may not work as the number of students taught increases. In this day of decreased funding and short staffing, it is more necessary than ever to turn to other modes of teaching students how to use the library.

\section{REFERENCES}

1. Many sources illustrate this point: George S. Bonn, Training Laymen in the Use of the Library, V.II, Part I of Ralph Shaw, ed., The State of the Library Art (New Brunswick, N.J.: Rutgers Univ. Pr., 1960), p.1-114; Arthur P.
Young, "Bibliographic Instruction: A Review of Research \& Applications," in John Lubans, ed., Progress in Educating the Library User (New York: Bowker, 1978), p.13-28: A. P. Marshall, ed., Library Trends: Current Library Use In- 
struction, V.29, no.1 (1980). (The entire issue provides a good update of current thinking and practice.)

2. A number of committees, subcommittees, and task forces in both ALA and ACRL are devoted to all aspects of bibliographic instruction. The June 1980 ALA Annual Conference in New York featured an ACRL Bibliographic Instruction Section meeting, "Learning Theory in Action: Applications in Bibliographic Instruction." There is also a task force on instructional theory, founded in 1980, operating under the ALA Library Instruction Round Table.

3. ACRL Bibliographic Instruction Section, "Research Agenda for Bibliographic Instruction," College \& Research Libraries News 41:94-95 (April 1980); Pamela Kabelski and Mary Rei- chel, "Conceptual Frameworks for Bibliographic Instruction," Journal of Academic Librarianship. 7:73-77 (May 1981).

4. Robert M. Gagné, The Conditions of Learning (New York: Holt, 1965).

5. William H. Allen, "Media Stimulus \& Types of Learning," Audiovisual Instruction 12, no.1:27-31 (Jan. 1967).

6. Donald T. Campbell and Julian C. Stanley, Experimental \& Quasi-Experimental Designs for Research (Chicago: Rand McNally, 1963), p.23.

7. Peter Pipe, Practical Programming (New York: Holt, 1966).

8. Campbell and Stanley, Experimental \& QuasiExperimental Designs, p.23-61. 